\title{
Hubungan Sikap Bidan Dalam Menerapkan Standart Operasional Prosedur Kebidanan Pada Tindakan Kegawatdaruratan Obstetri Di RSU Haji Surabaya
}

\author{
Kholifatul Ummah', Putu Ayu Dhana Reswari ${ }^{2}$ \\ ${ }^{1,2}$ Fakultas Ilmu Kesehatan Program Studi D-III Kebidanan Universitas \\ Dr.Soetomo Surabaya \\ Email:ummahifah@gmail.com
}

\begin{abstract}
The most emergent cases of emergencies are bleeding and eclampsia, in emergency cases such as these, actions that require a health worker, especially midwives, act quickly and responsively. Problems then arise when the actions taken have a substantial risk, so that midwives are required to be skilled and master the operational standard of obstetric procedures in handling neonatal maternal emergency cases.

One of the data presented is data from the ASEAN Millennium Development Goals (MDGs) in 2017. The data shows that in 2015 maternal mortality in Indonesia still reached 305 per 100 thousand. This figure is three times higher than the MDGs target of Indonesia, which is 102 per 100,000.

It was recorded in Surabaya City Health Office that in 2017 the number of neonatal cases handled was 2,785 cases or $67.5 \%$ of the total estimated 4,128 neonates, an increase from 2018 the number of neonatal cases handled by 2,187 (56.4\%) of the total estimated 3,878 neonates complications. When compared with 2016, the number of high risk pregnant women / complications found in Surabaya was 5,663 people and pregnant women / complications referred were $79.99 \%$ indicating a decrease in cases.

The method used is cross-sectional sample used purposive sampling, the test used is chi square, from this study it is expected to know the relationship between midwives' attitudes in applying operational standard obstetric procedures in obstetric emergency actions at RSU Haji Surabaya
\end{abstract}

Keywords: attitude, standard operational procedure

\section{PENDAHULUAN}

Tercatat pada Dinas Kesehatan Kota Surabaya ada tahun 2017 jumlah bayi resiko tinggi yang ditangani sebesar 2.785 kasus atau $67,5 \%$ dan tahun 2018 jumlah bayi resiko tinggi yang ditangani sebesar 2.187 (56,4\%)yang ditangani sebesar 2.187 $(56,4 \%)$. Jika dibandingkan dengan tahun 2016 dengan jumlah ibu hamil risiko tinggi/ komplikasi yang ditemukan di Kota Surabaya sebesar 5.663 orang dan bumil risti/ komplikasi yang dirujuk yaitu sebanyak 79,99\% menunjukkan ada penurunan kasus. Hasil survey awal bulan September sampai November 2018 angka kejadian Hemorogic post 
partum $5(0,23 \%), \quad$ sedangkan preeklampsia dan eklampsia sebesar $16(0,7 \%)$.

Berdasarkan fenomena diatas penulis tertarik untuk melakukan penelitian dengna judul hubungan sikap bidan dalam menerapkan Standar Operasional Prosedur (SOP) Kebidanan pada tindakan Kegawatdaruratan Obstetri di RSU Haji Surabaya.

\section{METODE PENELITIAN}

Penelitian ini merupakan penelitian kuantitatif dengan menggunakan pendekatan Cross Sectional (Nursalam,2003)

Analisis data dilakukan dengan menggunakan :

\section{Univariat}

Data responden yang bersifat numeric yaitu data demografi dicari mean dan standar deviasinya dan disajikan dalam bentuk tabel.

2. Bivariat

Dalam menganalisis data secara bivariat, pengujian data dilakukan dengan menggunakan uji statistic yaituChi Square dengan Taraf signifikansi $95 \% \quad(\alpha=0,05)$. Pedoman dalam menerima hipotesis: apabila nilai probabilitas (p) <0,05 maka Ho ditolak, apabila (p) > 0,05 maka Ho gagal ditolak. Data yang didapat disajikan dalam bentuk tabel.

\section{HASIL PENELITIAN}

\section{Analisis Univariant}

\section{a. Sikap Bidan dalam Penerapan SOP Kebidanan pada Tindakan Kegawatdaruratan Obstetri Di RSU Haji Surabaya} Hasil penelitian sikap bidan dalam menerapkan Standart
Opersional Prosedur disajikan dalam tabel berikut:

Tabel 5.3 Distribusi Frekuensi Sikap Bidan Dalam Penerapan SOP Bidan Pada Tindakan Kegawatdaruratan Maternal Neonatal Di RSU Haji $\begin{array}{lll}\text { Surabaya } & \\ \text { Sikap Frekuensi Presentase }\end{array}$

\begin{tabular}{lll}
$\begin{array}{l}\text { Sikap } \\
\text { Bidan }\end{array}$ & Frekuensi & $\begin{array}{l}\text { Presentase } \\
(\%)\end{array}$ \\
\hline $\begin{array}{l}\text { Sikap } \\
\text { Negatif }\end{array}$ & 15 & $50,0 \%$ \\
$\begin{array}{l}\text { Sikap } \\
\text { Positif }\end{array}$ & 15 & $50,0 \%$ \\
Jumlah & 30 & $100 \%$ \\
\hline
\end{tabular}

Sumber: data primer 2019

Berdasarkan tabel 5.3 menunjukkan sikap bidan dalam melaksanakan SOP Kebidanan yaitu dari 30 bidan memiliki sifat positif sebanyak 15 bidan $(50,0 \%)$

\section{b. Tingkat Kepatuhan Bidan Dalam Menerapkan SOP Kebidanan}

Hasil penelitian sikap bidan dalam penerapan SOP disajikan pada tabel berikut:

Tabel 5.3 Distribusi Frekuensi Sikap Bidan Dalam Penerapan SOP Bidan Pada Tindakan Kegawatdaruratan Maternal Neonatal Di RSU Haji Surabaya

Kepatuhan Frekuensi Presentase Bidan (\%)

\begin{tabular}{lcl}
\hline Tidak & 12 & $40,0 \%$ \\
$\begin{array}{l}\text { Patuh } \\
\text { Patuh }\end{array}$ & 18 & $60,0 \%$ \\
Jumlah & 30 & $100 \%$
\end{tabular}

Sumber: data primer 2019

Berdasarkan tabel 5.3 menunjukkan kepatuhan bidan dalam melaksanakan SOP Kebidanan yaitu dari 30 bidan 
memiliki kepatuhan sebanyak 18 bidan $(60,0 \%)$

\section{Analisis Bivariant}

Analisis bivariant dilakukan untuk melihat hubungan antar dua variabel, yaitu variabel bebas adalah sikap bidan dan variabel terikat adalah kepatuhan bidan. Hasil tabulasi silang dapat disajikan dalam tabel berikut

Tabel 5.1 Hubungan Sikap Bidan Dalam Menerapkan Standart Operasional Prosedur Kebidanan Pada Tindakan Kegawatdaruratan Maternal Neonatal Di RSU Haji Surabaya

\begin{tabular}{lllllllll}
\hline Kepatuhan bidan & \multicolumn{2}{l}{ Tidak patuh } & Patuh & & Total & p-value & Alpha \\
\hline Sikap bidan & $\mathrm{N}$ & $\%$ & $\mathrm{~N}$ & $\%$ & $\mathrm{~N}$ & $\%$ & & \\
Sikap negatif & 0 & 0 & 3 & $10 \%$ & 15 & $50 \%$ & 0.00 & 0.05 \\
Sikap positif & 12 & $40 \%$ & 15 & $50 \%$ & 15 & $50 \%$ & & \\
Jumlah & 12 & $40 \%$ & 18 & $60 \%$ & 30 & $100 \%$ & & \\
\hline
\end{tabular}

Berdasarkan tabel 5.1 dari 30 bidan diRSU Haji Surabaya diketahui bidan yang memiliki sikap positif dan menunjukkan kepatuhan terhadap standart operasional prosedur kebidanan sebanyak 15 bidan (50\%). Sedangkan bidan yang memiliki sikap negatif menunjukkan ketidakpatuhan $0(0 \%)$. Berdasarkan hasil analisis menggunakan uji chi square dengan hasil ( $p$-value $=0,00)$ didapatkan terdapat hubungan antara sikap bidan terhadap penerapan standart operasional prosedur kebidanan pada tindakan kegawatdaruratan maternal neonatal di RSU Haji Surabaya.

Sikap bidan dalam menerapkan standart operasional prosedur kebidanan di RSU Hji Surabaya sikap bidan dalam melaksanakan SOP Kebidanan yaitu dari 30 bidan memiliki sifat positif sebanyak 15 bidan $(50,0 \%)$.

Sikap kita pada pelaksanaan standart operasional prosedur kebidanan dilakukan sebagai suatu budaya kerja atau pola maka penerapan standart operasional prosedur kebidanan akan berjalan dengan baik.

Kepatuhan bidan dalam menerapkan standart operasional prosedur kebidanan di RSU Haji Surabaya dari 30 bidan memiliki kepatuhan sebanyak 18 bidan $(60,0 \%)$. Hasil penelitian ini bisa disimpulkan bahwa sebagian besar bidan di RSU Haji Surabaya melaksanakan kepatuhan sebesar $60 \%$. Kepatuhan dalam menerapkan SOP bidan akan mendukung upaya keselamatan pasien dan keselematan bidan dalam hal pencegahan infeksi nosokomial dan pencegahan kematian ibu dan bayi.

Sikap bidan dalam menerapkan standart operasional prosedur dari 30 bidan yang memilki sikap positif 30 bidan diRSU Haji Surabaya diketahui bidan yang memiliki sikap positif dan menunjukkan kepatuhan terhadap standart operasional prosedur kebidanan sebanyak 15 bidan (50\%). Sedangkan bidan yang memiliki sikap negatif menunjukkan ketidakpatuhan $0 \quad(0 \%)$. Dikarenakan oleh pengetahuan tentang penerapan standart operasional prosedur kebidanan yang baik dikarena bidan mengetahui tentang dampak jika tidak menerapkan SOP dengan baik untuk bidan yang masih belum bisa menerapkan SOP dengan baik maka perlu untuk diberikan pembinaan dan 
tentang penerapan standart operasinal prosedur kebidanan.Berdasarkan hasil analisis menggunakan uji chie square dengan hasil ( $p$-value $=0,00$ ) diketahui ada hubungan antara sikap

\section{SIMPULAN DAN SARAN}

A. Simpulan

1.Sikap bidan dalam melaksanakan SOP

Kebidanan yaitu dari 30 bidan memiliki sifat positif sebanyak 15 bidan $(50,0 \%)$

2. Kepatuhan bidan dalam melaksanakan SOP Kebidanan yaitu dari 30 bidan memiliki kepatuhan sebanyak 18 bidan $(60,0 \%)$

3. Berdasarkan hasil analisis menggunakan uji chi square dengan hasil ( $\mathrm{p}$-value $=0,00$ ) terdapat hubungan antara sikap bidan terhadap penerapan standart operasional prosedur kebidanan pada tindakan kegawatdaruratan maternal neonatal di RSU Haji Surabaya

B. Saran

Diharapkan melalui penelitian ini, pembaca dapat mengeksplore dan mengembangkan suatu penelitian untuk kasus dan metode yang baru di bidang kebidanan sesuai dengan kewenangan bidan dalam melakukan asuhan pada masyarakat.

\section{DAFTAR PUSTAKA}

Arfianti, D. (2017). Faktor-faktor yang berhubungan dengan kepatuhan Cuci Tangan Perawat di RSI Sultan Agung Semarang, Jurnal Universitas bidan terhadap penerapan standart operasional prosedur kebidanan pada tindakan kegawatdaruratan maternal neonatal di RSU Haji Surabaya.

\section{Muhammadiyah \\ Semarang.}

Azwar, S. (2015). Sikap Manusia Teori Dan Pengukurannya, Pustaka Pelajar Offset, Yogyakarta, Indonesia.

Burke, J. (2016). Infection Control a Problem for Patient Safety, The New England Journal of Medicine, 348, $651-656$.

Ida Rukmawati, et al, (2015). Hubungan Antara Tingkat Pengetahuan Bidan Tentang Pelayanan ANC Dengan Praktek Pemeriksaan Kehamilan Sesuai Standart Minimal 7 T Di Puskesmas Sidoharjo Kabupaten Sragen. Jurnal Kesehatan

Rusnadiah, Yulia Sari.(2017). Hubungan Motivasi Kerja Bidan Dalam Pelayanan Antenatal Dengan Kepatuhan

Pendokumentasian Kartu Ibu Hamil Di Puskesmas UPTD Kabupaten Bandung. Jurnal Kesehatan STIKES A. Yani Cimahi 